\title{
Neural Tube Defect: Epidemiologic and Demographic Implication
}

\author{
Dr.B.Shanta Kumari ${ }^{1}$, Dr. Rajalaxmi Panda ${ }^{2}$, Dr. Sadananda Rath ${ }^{3}$ \\ ${ }^{I}$ (Post Graduate Student, Department of Anatomy, M.K.C.G Medical College, Berhampur, Odisha, India) \\ ${ }^{2}$ (Associate Professor, Department of Anatomy, M.K.C.G Medical College, Berhampur, Odisha, India) \\ 3 ( Professor and Head, Department of Anatomy, M.K.C.G Medical College, Berhampur, Odisha, India )
}

\begin{abstract}
Congenital abnormalities can develop at any time after the first month of pregnancy. From conception to birth, the embryo, and the fetus have to adapt, at a molecular and transcriptional level, to various changes in their cellular mileau. At conception, this environment depends on the micronutritional status of maternal and paternal germ cells and after conception on maternal nutritional status, metabolism, and lifestyle. Neural tube defect (NTD) is one of the commonest malformations with worldwide prevalence of 1-3/1000 live births. They are caused by failure of neural tube to close during neurulation in 21-28 embryonic days. The most common types of NTD are anencephaly and spina bifida, which are caused by failure of closure of cranial pore and spinal part of neural tube, respectively. Unfortunately the number of studies on this aspect is too scanty in our state. Therefore the present research work has been undertaken in the Department of Anatomy, M.K.C.G. Medical College, Berhampur during the period 2011-2013 with the help of Department of Obstetrics and Gynaecology and Radiodiagnosis to study the Neural tube defect aiming to know the prevalence and demographic status, to reduce maternal and fetal morbidity and mortality by selected obstetrical management.

Keyword: Anencephaly, Congenital, Neural tube defect, Neurulation, Spina bifida
\end{abstract}

\section{Introduction}

Neural tube defects (NTDs) are major congenital defects with multifactorial etiology . Neural tube defects (NTDs) top the list of birth defects in India contributing to both morbidity and mortality. The annual worldwide incidence of the two commonest forms of NTDs i.e. spina bifida and anencephaly put together is about 400,000 newborns. ${ }^{[1]}$ Folate deficiency has a well-established teratogenic effect, leading to an increasing risk of neural tube defects.

Observational and interventional studies have all been consistent with a 50-70\% protective effect of adequate women consumption of folates on neural tube defects. ${ }^{[2]}$ Since strategies to modify women's dietary habits and vitamin use have achieved little progress.

Unfortunately the number of studies on this aspect is too scanty in our state. Therefore the present research work has been undertaken to correlate and study the craniospinal anomalies aiming to know the prevalence and also counselling the couples to reduce maternal and fetal morbidity and mortality by selected obstetrical management.

\section{Material \& Method}

The study was carried out at M.K.C.G. Medical College and Hospital, Berhampur in the department of Anatomy in collaboration with the department of Radiodiagnosis and Obstetrics and Gynecology for a period of 5 years from July, 2008 to August, 2013. The study was retrospective from July, 2008 to August, 2011 (3 years) and prospective from September,2011 to August, 2013 (2 years).For retrospective cases data was retrieved from the record section (Birth record, Stillborn record and Fetal death reports) of Obstetrics and Gynaecology department.

For prospective cases, after obtaining permission from the ethical committee of M.K.C.G. Medical College and Hospital, Berhampur and with an informed consent, women attending the antenatal clinic in this institute who were referred for routine ultrasonography and those women referred as high risk patients to emergency and PP centre were selected for the study. The cases were also taken from stillbirth, spontaneous and therapeutic abortions. 


\section{Observation \& Analysis \\ Table-I}

Number of NTD's during the year of occurrence from August, 2008 to July, 2013

\begin{tabular}{|l|c|c|c|c|c|c|}
\hline Period & Anencephaly & Spina bifida & Encephalocele & Holoprosencephaly & Iniencephaly & Total \\
\hline Aug.08 - July 09 & 8 & 19 & 4 & 3 & 2 & 36 \\
\hline Aug.09 - July, 10 & 16 & 22 & 5 & 4 & 3 \\
\hline Aug.10 - July,11 & 15 & 13 & 3 & 2 & 2 \\
\hline Aug.11 - July, 12 & 11 & 12 & 5 & 1 & 35 \\
\hline Aug.12 - July, 13 & 3 & 10 & 2 & 0 & 31 \\
\hline TOTAL & 53 & 76 & 19 & 10 & 0 & 15 \\
\hline
\end{tabular}

Table-II

Number and Percentage of Sub-Types of Anencephaly and Spina bifida

\begin{tabular}{|l|l|c|c|}
\hline \multicolumn{2}{|c|}{ Sub-Types } & Number & Percentage \\
\hline \multirow{3}{*}{ Anencephaly (n=53) } & Meroanencephaly & 7 & 13.21 \\
\cline { 2 - 4 } & Holoanencepahy & 40 & 75.47 \\
\cline { 2 - 4 } & Craniorachischisis & 6 & 11.32 \\
\hline \multirow{3}{*}{ Spina bifida (n=76) } & Occulta & 11 & 14.47 \\
\cline { 2 - 4 } & Meningocele & 13 & 17.11 \\
\cline { 2 - 4 } & Meningomylocele & 52 & 68.42 \\
\hline
\end{tabular}

Table-III

Spina bifida as per location

\begin{tabular}{|l|l|l|l|}
\hline \multirow{2}{*}{ Region } & \multicolumn{1}{|c|}{ Occulta $(\mathbf{n = 1 1 )}$} & \multicolumn{1}{c|}{ Cystica } \\
\cline { 3 - 4 } & \multicolumn{1}{|c|}{ Meningocele(n=13) } & \multicolumn{1}{c|}{ Meningomylocele(n=52) } \\
\hline Cervical & $2(18.18)$ & $2(15.38)$ & $5(9.62)$ \\
\hline Thoracic & $5(45.45)$ & $2(15.38)$ & $6(11.54)$ \\
\hline Lumbar & $4(36.36)$ & $8(61.54)$ & $35(67.31)$ \\
\hline Sacral & $0(0.00)$ & $1(7.69)$ & $6(11.54)$ \\
\hline
\end{tabular}

DEMOGRAPHIC PARAMETERS OF NEURAL TUBE DEFECTS -

Table-IV

NTD following Consanguineous Marriage

\begin{tabular}{|c|c|c|c|}
\hline History of Consanguineous marriage & Anencephaly $(\mathbf{n = 5 3})$ & Spina bifida (n=76) & Total \\
\hline Yes & $5(9.43)$ & $10(13.16)$ & $15(11.63)$ \\
\hline No & $48(90.57)$ & $66(86.84)$ & $114(88.37)$ \\
\hline
\end{tabular}

Table-V

Incidence of different craniospinal anomalies in different social classes

\begin{tabular}{|l|c|c|c|c|c|}
\hline Socio-Economic Status & $\begin{array}{c}\text { Anencephaly } \\
(\mathbf{n = 5 3})\end{array}$ & $\begin{array}{c}\text { Spina bifida } \\
(\mathbf{n = 7 6})\end{array}$ & $\begin{array}{c}\text { Encephalocele } \\
(\mathbf{n = 1 9})\end{array}$ & $\begin{array}{c}\text { Holoprosencephaly } \\
(\mathbf{n}=\mathbf{1 0})\end{array}$ & $\begin{array}{c}\text { Hydrocephalus } \\
(\mathbf{n}=\mathbf{8 7})\end{array}$ \\
\hline Low $(\mathrm{n}=196)$ & $42(79.25)$ & $63(82.89)$ & $13(68.42)$ & $9(90)$ & $72(82.26)$ \\
\hline Medium $(\mathrm{n}=46)$ & $11(20.75)$ & $13(17.11)$ & $6(31.58)$ & $1(10)$ & $15(17.24)$ \\
\hline High $(\mathrm{n}=0)$ & $0(20.75)$ & $0(0.00)$ & $0(0.00)$ & $0(0.00)$ & $0(0.00)$ \\
\hline
\end{tabular}

$\mathrm{n}=$ donates the number of total cases in specified category

Table - VI

Demographic Status of the neural tube defect cases

\begin{tabular}{|l|c|c|c|c|c|}
\hline \multirow{2}{*}{ Groups (No.) } & \multicolumn{5}{c|}{ Maternal age in Years } \\
\cline { 2 - 6 } & $\mathbf{6 2 0}$ & $\mathbf{2 0 - 2 4}$ & $\mathbf{2 5 - 2 9}$ & $\mathbf{3 0 - 3 4}$ & $\mathbf{3 5}$ \\
\hline Anencephaly (n=53) & $10(18.87)$ & $13(24.53)$ & $8(15.09)$ & $19(35.85)$ & $3(5.66)$ \\
\hline Spina bifida (n=76) & $14(18.42)$ & $25(32.89)$ & $7(9.21)$ & $19(25.00)$ & $11(14.47)$ \\
\hline Encephalocele (n=19) & $5(26.32)$ & $4(21.05)$ & $1(5.26)$ & $6(31.58)$ & $3(15.79)$ \\
\hline Holoprosencephaly (n=10) & $1(10.00)$ & $4(40.00)$ & $1(10.00)$ & $3(30.00)$ & $1(10.00)$ \\
\hline Iniencephaly $(\mathrm{n}=10)$ & $0(0.00)$ & $4(40.00)$ & $0(0.00)$ & $3(30.00)$ & $3(30.00)$ \\
\hline Hydrocephalus $(\mathrm{n}=87)$ & $12(13.79)$ & $33(37.93)$ & $18(20.69)$ & $19(21.84)$ & $5(5.75)$ \\
\hline Total & $38(15.70)$ & $78(32.23)$ & $40(16.53)$ & $58(23.97)$ & $28(11.57)$ \\
\hline
\end{tabular}




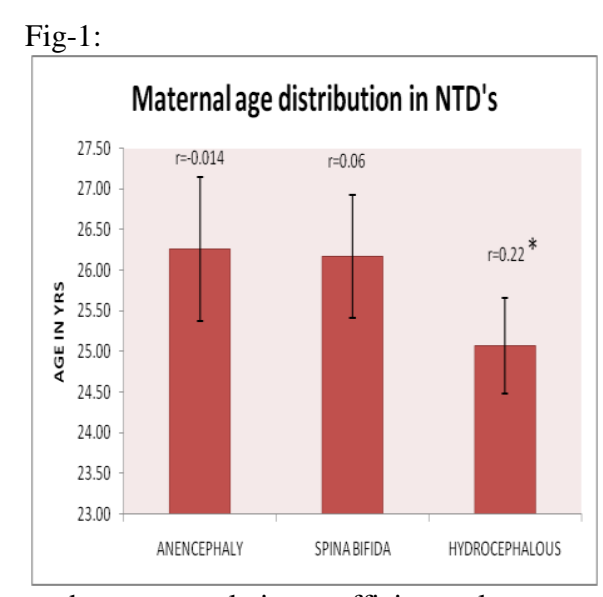

$\mathrm{r}=$ denotes correlation coefficient values.

$*$ denotes $\mathrm{p}<0.05$ is significant
Fig-2:

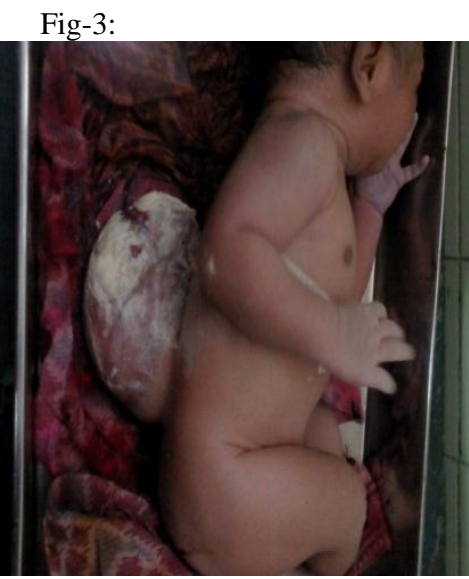

Anencephalic case with angiomatous stroma

Closed Neural tube defect
Fig-4:

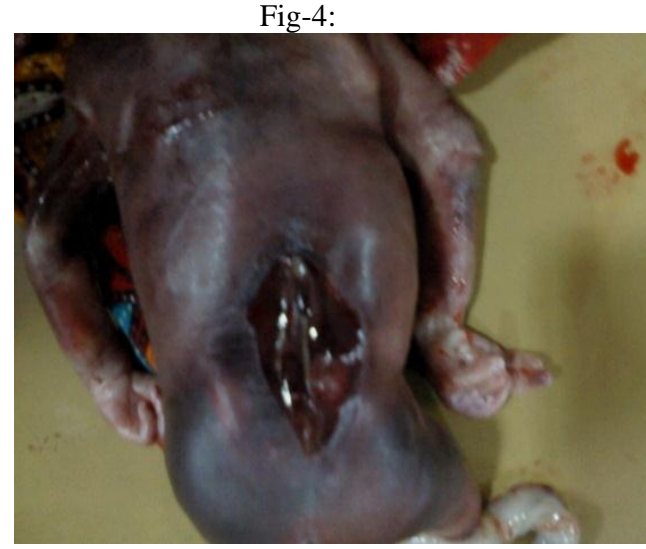

Open Neural tube defect

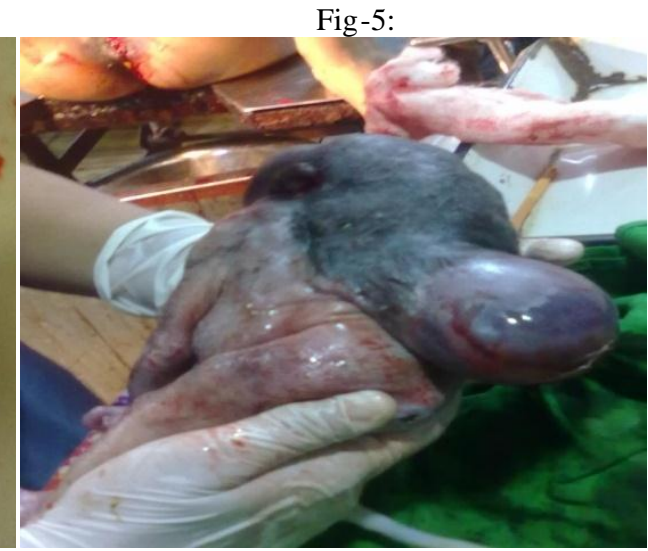

Iniencephaly

\section{Discussion}

On analysis of data, for year wise incidence of neural tube defects, a decreasing trend was observed from 2009-2013. According to our study, the overall prevalence of NTD's is 9.12 per 1000 deliveries. The incidence of NTD's reported in India i.e. $6.57-8.21 / 1000$ live births is higher than that in our study, that is 4.47/1000 live births. (Table-I)

Decreasing order of NTD's rates was for spina bifida (45.5\%), anencephaly $(31.7 \%)$, encephalocele $(16.2 \%)$, holoproscecephaly (5.9\%) and iniencephaly(Fig-5) (5.4\%). which is compatible with study in Urmia (I.Abdi, 2008), as well as in California (Feuchtbaum LB, 1999) ${ }^{[1],[2]}$

As regards the subtypes of Anencephaly, Holoanencephaly were maximum followed by Meroanencephaly and Craniorachischisis and among spina bifida cases, meningomyelocele outnumbered those of meningocele and spina bifida occult as recorded from Table-II. (Fig-2,3,4)

The lumbar region is more prone for spina bifida(Table-III) and this finding corroborates with a study done by Isada Nelson B. (1993), but contradicts the study done by Jean - Pierre Bernard (2012). ${ }^{[3],[4]}$

As regards the consanguineous marriage, $11.63 \%$ of the affected group had a positive history. (Table IV) Similar finding were quoted in the study of N.N. Dissanayake (2009). ${ }^{[5]}$, B.Mahadevan (2005) $-10.3 / 1000$ couples and Agarwal SS (1999), 16.3-20.6/1000 couples. ${ }^{[6],[7]}$

While correlating the socio-economic status (Table V) with Neural tube defect our observation shows population with low socio-economic status mainly having babies with neural tube defects. Similar observations by N.N. Dissanayak (2009) ${ }^{[5]}$ Shaw G M.et.al (2002),S. Halwachs (2010),D.A.Hansen(2008),R.Schultz.et.al (2003) corroborate with our study. ${ }_{[}^{[5],[8],[9],[10],[11]}$

While correlating the maternal age with the occurrence of neural tube defects our observations show maximum number of cases in the age group of 20-24 years while anencephlic cases are mostly in women more than 30 years of age and spina bifida in mothers between age group of 20-24 years followed by the age group of more than 30 years which is in consonance with the study of I. Abdi (2008) and Sharada B. Menasinkai (2010) and Golalipour et al (2010). ${ }^{[1],[12],[13]}$ 
The analysis by Vieira AR, Castillo Taucher S, 2005 revealed that there is an increased risk of having an offspring with NTD's for mothers of 40 years of age or older. There is also evidence that mothers of 19 years old or younger have a higher risk of having a child with spina bifida. ${ }^{[14]}$

In our study the mean maternal age for neural tube defects is 26 years and is significantly higher for $(\mathrm{P}<0.05)$ hydrocephalus (Table VI, Graph 1). Orv Hetil.Joó JG states maternal median age was $27 \pm 5.8$ years, ranging from 15 to 47 years. ${ }^{[15]}$

\section{Conclusion}

Neural tube defects are an enigmatic problem that occurs as a result of the interplay between a number of genetic and environmental factors. Our study reveals the high incidence and their possible etiological factors such as consanguineous marriage, low socioeconomic status and maternal age.

\section{References}

[1]. Abdi Rad I., ,H.R.Farrokh-Islamlou ,M. Khoshkalam : Neural Tube Defects Prevalence In A Hospital-Based Study In Urmia; Iran J Child Neurology June 2008

[2]. Feuchtbaum LB, Currier RJ, Riggle S, Roberson M, Lorey FW, Cunningham GC. Neural tube defect prevalence in California (19901994): eliciting patterns by type of defect and maternal race/ethnicity. Genet Test 1999; 3 (3): 265-272.

[3]. Isada, Nelson B.; Qureshi, Faisal; Jacques, Suzanne M.; Holzgreve, Wolfgang; Tout, Mary Jo; Johnson, Mark P.; Evans, Mark I. (1993). "Meroanencephaly: Pathology and Prenatal Diagnosis". Fetal Diagnosis and Therapy8 (6): 428.

[4]. Bernard Jean-Pierre, MD; Howard S. Cuckle, BA, MSc, DPhil; Julien J. Stirnemann, MD; Laurent J. Salomon, MD, PhD; Yves Ville, MD; Screening for fetalspina bifida by ultrasound examinationin the first trimester of pregnancy using fetalbiparietal diameter; 306.e1 American Journal of Obstetrics \&Gynecology 2012.

[5]. N N Dissanayake, S C Wickramasinghe2, D M W H Bandara3, Study on neural tube defects of neonates and folic acid awareness at aTeaching Hospital in Sri Lanka Sri Lanka Journal of Child Health, 2010; 39:11-16

[6]. Mahadevan B, Bhat BV. Neural tube defects in Pondicherry. Indian J Pediatr 2005; 72: 557-559.

[7]. Agarwal S S. Neural tube defect: a preventable congenital malformation. Indian Pediatr 1999; $36: 643-648$.

[8]. Shaw GM, Nelson V, Olshan AFPaternal occupational group and risk of offspring with neural tube defects. PaediatrPerinatEpidemiol. 2002 Oct:16(4):328-33.

[9]. Halwachs S., C. Lakoma, R. Gebhardt, I. Schäfer, P. Seibel, and W. Honscha, "Dioxin mediates downregulation of the reduced folate carrier transport activity via the arylhydrocarbon receptor signalling pathway," Toxicology and Applied Pharmacology, vol. 246, no. $1-2$, pp. 100-106, 2010

[10]. Hansen D. A. , "Paternal environmental exposures and gene expression during spermatogenesis: research review to research framework," Birth Defects Research Part C, vol. 84, no. 2, pp. 155-163, 2008.

[11]. Schultz R., J. Suominen, T. Värre et al., "Expression of aryl hydrocarbon receptor and aryl hydrocarbon receptor nuclear translocator messenger ribonucleic acids and proteins in rat and human testis," Endocrinology, vol. 144, no. 3, pp. 767-776, 2003.

[12]. Sharada B. Menasinkai; A Study of Neural tube defects, J. Anat. Soc. India 59(2) 162-167 (2010).

[13]. GolalipourMJ, Najafi L.,Keshtkar AA : Prevalence of anencephaly in gorgan, Northern Iran.Arch Iran Med 2010;13:34-7

[14]. Vieira AR, Castillo Taucher S. Maternal age and neural tube defects: evidence for a greater effect in spina bifida than in anencephaly.Rev Med Chil. 2005 Jan;133(1):62-70. Epub 2005 Mar 10

[15]. Orv Hetil.Joó JG, Beke A, Szigeti Z, Csaba A, Mezei G, Tóth-Pál E, Papp Z, Papp C.; Craniospinal malformations in a twelve-year fetopathological study; the efficiency of ultrasonography in view of fetopathological investigations. 2008 Jan 6; 149(1):23-7. 